\title{
Consequences of Workplace Violence on Nursing Staff Who Working in Educational Baghdad Hospital
}

\author{
Suhad H. Khairi *
}

\begin{abstract}
Background and Objective: Violence at work is becoming an alarming phenomenon worldwide. Affecting the dignity of millions of people, violence is a major source of inequality, discrimination, stigmatization and conflict in the workplace. Therefore, a cross section study was conducted to assess the types of work place violence and to find out the consequences of work place violence on nursing staff who working in educational Baghdad hospital

Material and Method: Sample was selected from intentional nurses those who work in Baghdad Teaching Hospital. (100) of nurses who agreed to participate in this study during the period from February to March 2012 in the city of Baghdad. Data was collected through the filled application questionnaire form, descriptive statistical methods used in data analysis.

Results: the results indicate that the highest percentage (25\%) of the study sample in the age group (4044) years, the mean age and SD of study sample is $36.79 \pm 8.70190$. and $(59 \%)$ of the study sample were male, and the majority (95\%) of them living in Baghdad. the highest percentage (47\%) of study sample were working in surgical ward. (46\%) of study sample were at secondary school level. the highest percentage (77\%) of study sample were married. According to Workplace Violence Sources the highest grade (92) at high level of RS of the work place Sources regarding Patient and his Relative refers to Bad Working conditions (excessive heat or cold, noise, bad furniture). Concerning Colleagues or Supervisors the highest grade (94.5) at high level of RS of the work place regarding colleagues or supervisors violence which refers to absence of proper insurance. According to the Consequences of Workplace Violence Level the highest grade (86.5) at moderate level of RS of the consequences on a personal level for nurses which refers to anger. The consequences on work level the highest grade (87) at moderate level of RS refers to Underestimation and disrespect of the profession of nursing in the society. Concerning consequences on health care setting the highest grade (90) at high level of RS refers to more shortage of healthcare professionals (many healthcare professionals shift to other fields.

Conclusion: The study highlights the sources of workplace on nurses. All study samples had experienced workplace violence either from patient and his relatives or from colleagues or supervisors. Exposure to work place violence often has a great consequences regarding personal, working and health setting level on the satisfaction of nurses and the quality of health care service.
\end{abstract}

Key words: Consequences, Workplace, Violence, Nursing Staff

\section{INTRODUCTION}

Violence at work is becoming an alarming phenomenon worldwide. Affecting the dignity of millions of people, violence is a major source of inequality, discrimination, stigmatization and conflict in the workplace. Increasingly it is becoming a central human rights issue. The enormous cost of workplace violence for the individual, the workplace and the community at large is becoming more and more apparent (International Labour Organization (ILO), 2000). A report from Department of Labor which estimated rate of violence as 38 cases per 10,000 workers for nursing and personal care facilities. In contrast, private industry reported to have three cases per 10,000 workers, which is relatively very low. This evidence clearly indicates that nurses are the most vulnerable population among health care team members to encounter violence (Henry and Ginn, 2006). A different forms of violence for example, bullying, horizontal violence, oppression, sexual harassment, racism, and physical assault (Jackson, Clare and Mannix, 2004). The oppression and horizontal violence considered as the most common form of violence directed to coworkers (Oxbridge Writers, 2011). Nursing is regarded as caring profession. A nurse is appreciated for her

* Lecturer/Ph.D/Maternal and Child Health Nursing Department/College of Nursing/University of Baghdad. 
holistic approach in providing care to people in need. While nurses take care of the patients in the health care setting, it is administration's responsibility to take care of the care providers. Woelfle and McCaffrey (2007) Concluded that in addition to caring about patients, nurses will have to care about the profession of nursing and find new and innovative ways in their practice to support nursing. As a result nurses may begin to support each other and need to work collectively against violence because it is intolerable.

\section{MATERIALS AND METHOD}

A cross section study was conducted to assess the types of work place violence and to find out the consequences of work place violence on nursing staff who working in educational Baghdad hospital.

Sample was selected from intentional nurses those who work in Baghdad Teaching Hospital. (100) of nurses who agreed to participate in this study during the period from February to March 2012 in the city of Baghdad. Data was collected through the filled application questionnaire form, descriptive statistical methods used in data analysis. The limitations of the study were the first; some of the questionnaire forms are not completely answered so excluded from the sample; the second was not all nurses participate in the study because of morning shift.

\section{RESULTS}

Age level

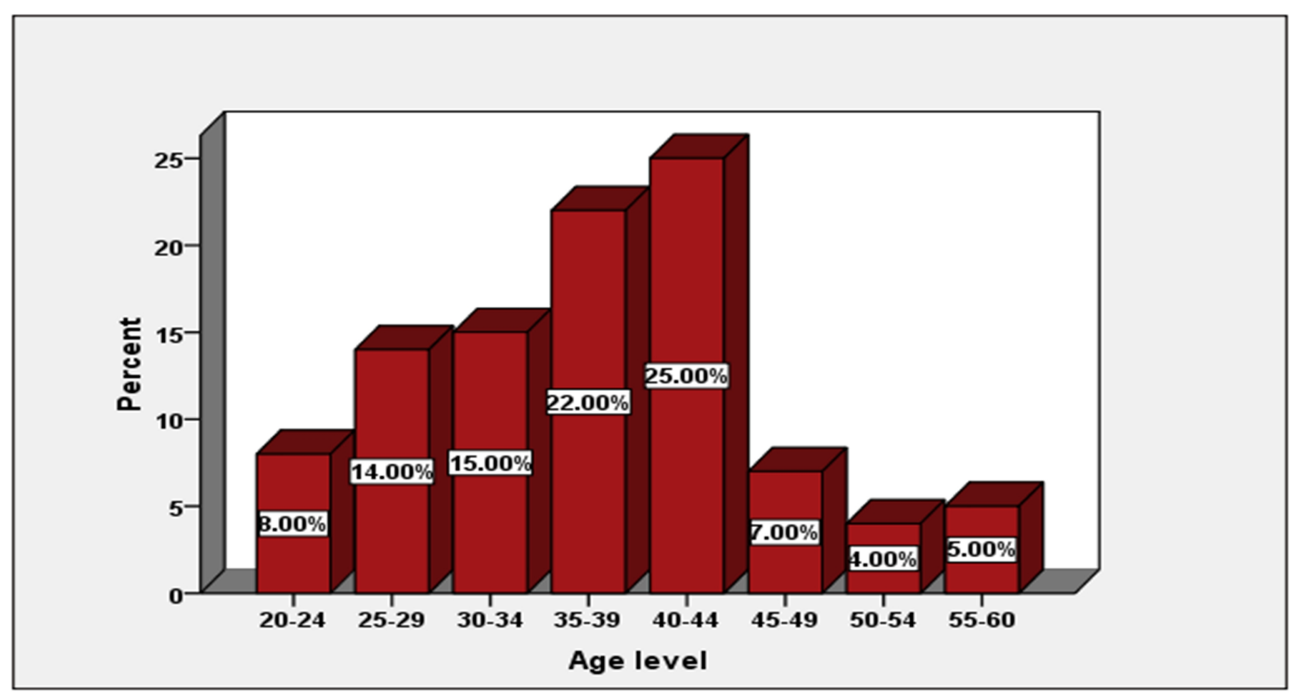

Figure (1): Distribution of (100) Study Sample According to Age Level

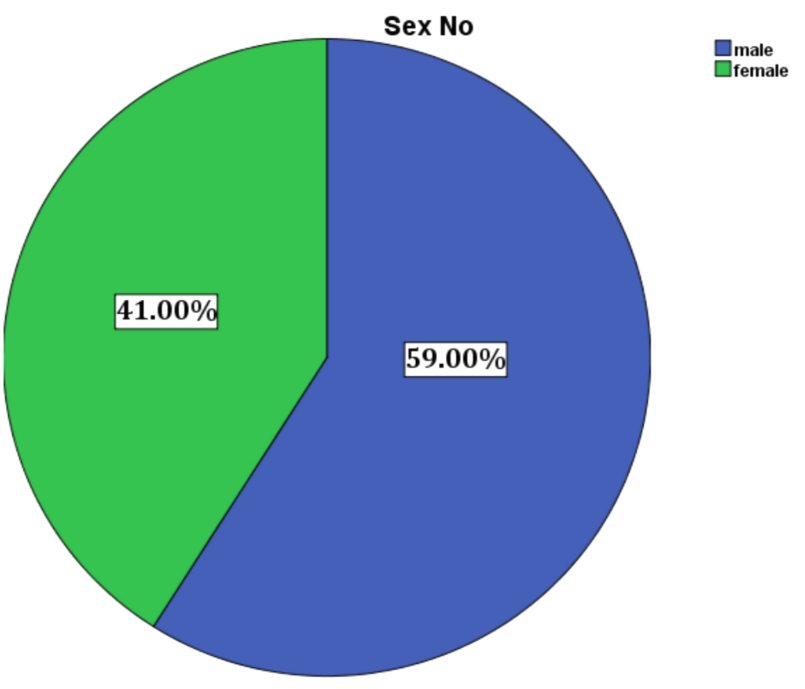

Figure (2): Distribution of Study Sample According to Sex 


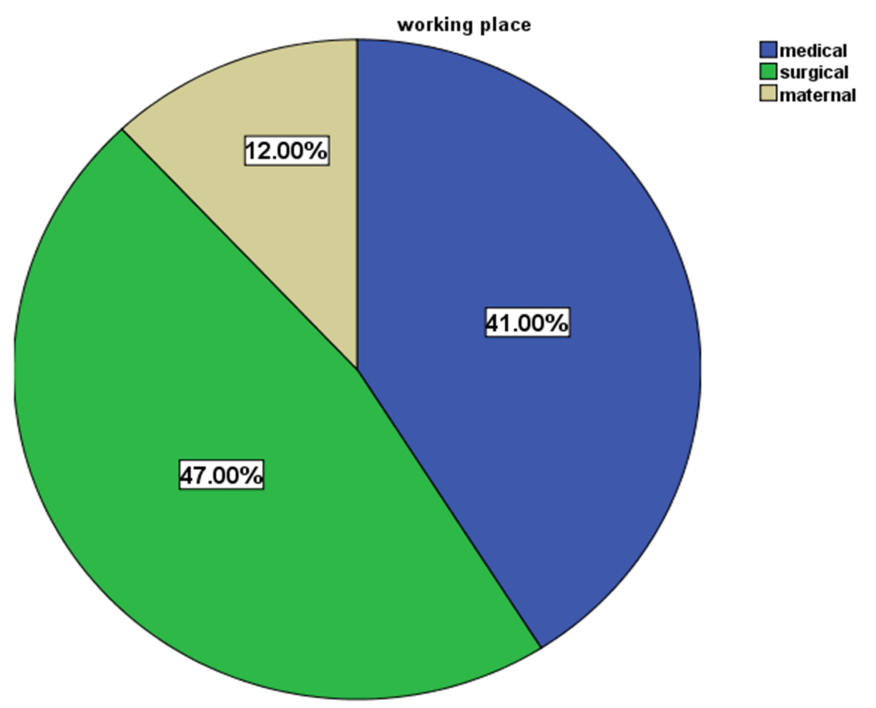

Figure (3): Distribution of Study Sample According to Working Place

Iocation 1

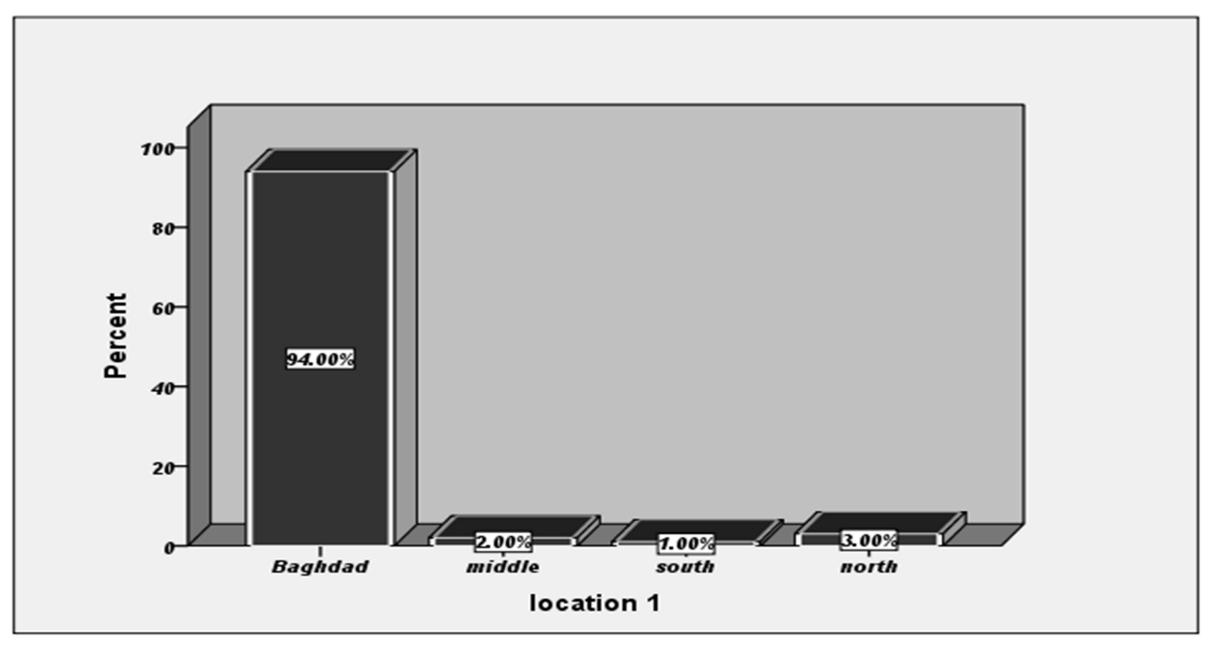

Figure (4): Distribution of Study Sample According to Resident

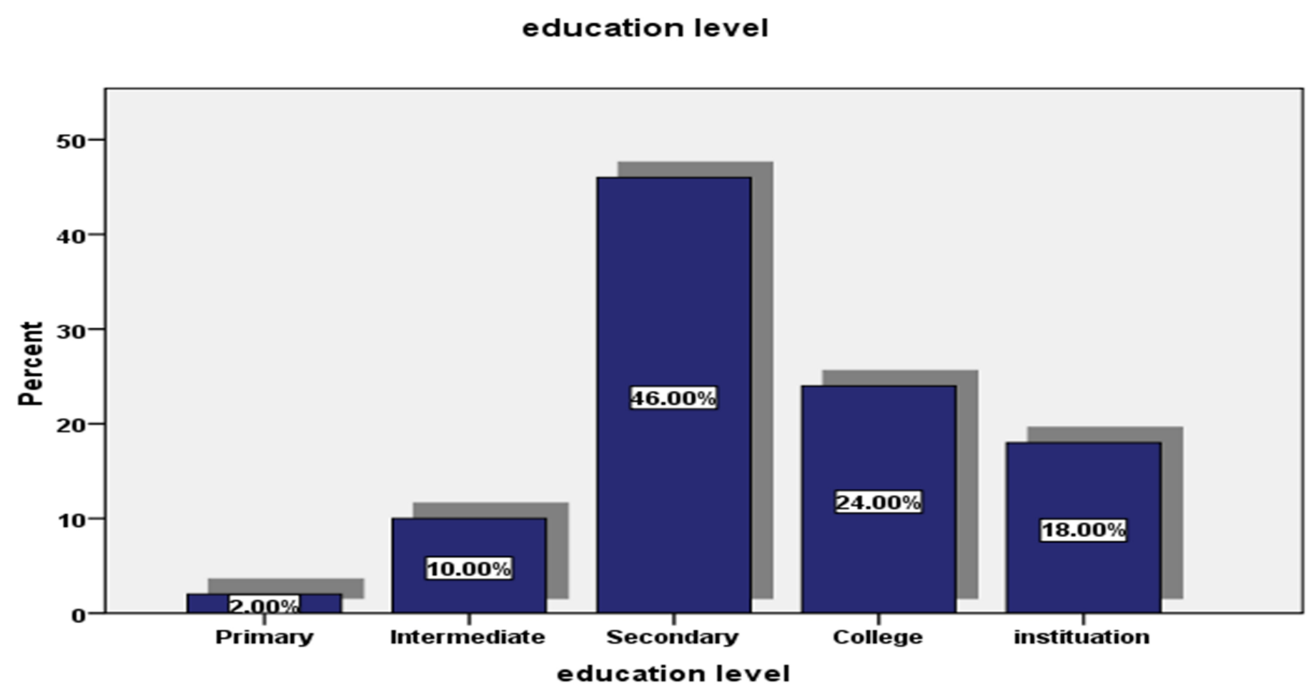

Figure (5): Distribution of Study Sample According to Educational Level 
social status

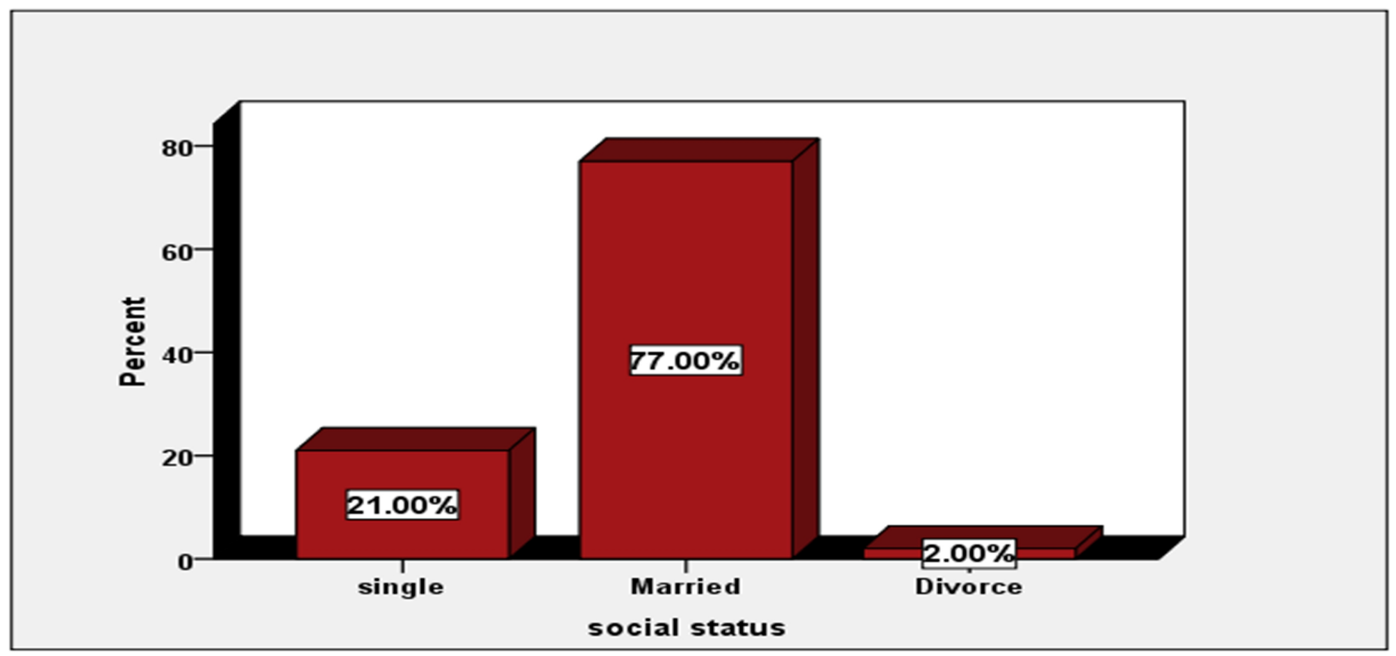

Figure (6): Distribution of Study Sample According to Social Status

Table (1): Distribution of Study Sample According to the Workplace Violence Sources

\begin{tabular}{|c|c|c|c|c|c|c|c|}
\hline \multirow{2}{*}{ A- Patient and his Relative } & \multicolumn{2}{|c|}{ Yes } & \multicolumn{2}{|c|}{ No } & \multirow{2}{*}{ MS } & \multirow{2}{*}{$\mathbf{R S}$} & \multirow{2}{*}{ Total } \\
\hline & No & $\%$ & No & $\%$ & & & \\
\hline $\begin{array}{l}\text { 1.Lack of trust in the competence of the nurses } \\
\text { and midwives }\end{array}$ & 51 & 51 & 49 & 49 & 1.51 & 75.5 & 100 \\
\hline 2.Lack of compliance & 57 & 57 & 43 & 43 & 1.57 & 78.5 & 100 \\
\hline $\begin{array}{l}\text { 3. Breaking the rules (Not waiting for their turn to } \\
\text { arrive) }\end{array}$ & 71 & 71 & 29 & 29 & 1.71 & 85.5 & 100 \\
\hline 4.Aggressive and impolite talk & 77 & 77 & 23 & 23 & 1.77 & $88.5 * * *$ & 100 \\
\hline $\begin{array}{l}\text { 5.Use unmannered language (insult, offend or } \\
\text { abusive language) }\end{array}$ & 71 & 71 & 29 & 29 & 1.71 & 85.5 & 100 \\
\hline 6.Distarbing & 77 & 77 & 23 & 23 & 1.77 & $88.5 * * *$ & 100 \\
\hline $\begin{array}{l}\text { 7. Offended by the way patients look ,talk and } \\
\text { afraid of sexual harassment }\end{array}$ & 44 & 44 & 56 & 56 & 1.44 & 72 & 100 \\
\hline 8.Terrifying & 54 & 54 & 46 & 46 & 1.54 & 77 & 100 \\
\hline 9. interfere with the nurse's work and treatment & 82 & 82 & 18 & 18 & 1.82 & $* * * 91$ & 100 \\
\hline $\begin{array}{l}\text { 10. Many nurses were wrongfully accused of } \\
\text { stealing }\end{array}$ & 57 & 57 & 43 & 43 & 1.57 & 78.5 & 100 \\
\hline $\begin{array}{l}\text { 11.Bad Working conditions (excessive heat or } \\
\text { cold, noise, bad furniture) }\end{array}$ & 84 & 84 & 16 & 16 & 1.84 & $92 * * *$ & 100 \\
\hline $\begin{array}{l}\text { 12. Tone of voice (authoritarian, degrading, cruel, } \\
\text { disrespectful...) }\end{array}$ & 56 & 56 & 44 & 44 & 1.56 & 78 & 100 \\
\hline \multicolumn{8}{|l|}{ B-Colleagues or Supervisors } \\
\hline 1.High tone voice & 32 & 32 & 68 & 68 & 1.32 & 66 & 100 \\
\hline 2.Insult & 26 & 26 & 74 & 74 & 1.26 & 63 & 100 \\
\hline 3. Offensive talk & 30 & 30 & 70 & 70 & 1.3 & 65 & 100 \\
\hline 4. Eye contact with despite & 27 & 27 & 73 & 73 & 1.27 & 63.5 & 100 \\
\hline 5. Hits the table with the fist & 20 & 20 & 80 & 80 & 1.2 & 60 & 100 \\
\hline 6. Hitting by Hand & $* 19$ & 19 & 81 & 81 & 1.19 & 59.5 & 100 \\
\hline 7. Mistreatment & 40 & 40 & 60 & 60 & 1.4 & 70 & 100 \\
\hline 8. Discrimination between employees & 54 & 54 & 46 & 46 & 1.54 & 77 & 100 \\
\hline 9. Lack of appreciation and appraisal & 46 & 46 & 54 & 54 & 1.46 & 73 & 100 \\
\hline 10. Low Salary & 83 & 83 & 17 & 17 & 1.83 & $91.5 * * *$ & 100 \\
\hline 11. Work overload & 79 & 79 & 21 & 21 & 1.79 & $89.5 * * *$ & 100 \\
\hline
\end{tabular}




\begin{tabular}{|l|c|c|c|c|c|c|c|}
\hline 12. Hostile unjustified behavior & 52 & 52 & 48 & 48 & 1.52 & 76 & 100 \\
\hline 13. Poor salaries & 75 & 75 & 25 & 25 & 1.75 & $87.5^{* * *}$ & 100 \\
\hline 14. Lack of job security & 87 & 87 & 13 & 13 & 1.87 & $* * * 93.5$ & 100 \\
\hline 15. Absence of proper insurance & 89 & 89 & 11 & 11 & $\mathbf{1 . 8 9}$ & $* * \mathbf{9 4 . 5 *}$ & 100 \\
\hline 16. Jealousy and competition among colleagues & 51 & 51 & 49 & 49 & 1.51 & 75.5 & 100 \\
\hline 17.Dissemination gossiping in healthcare settings & 55 & 55 & 45 & 45 & 1.55 & 77.5 & 100 \\
\hline $\begin{array}{l}\text { 18. Lack management skills of the supervisors and } \\
\text { directors }\end{array}$ & 70 & 70 & 30 & 30 & 1.70 & 85 & 100 \\
\hline 19. Less motivation and reward to work nurses & 88 & 88 & 12 & 12 & 1.88 & $94 * * *$ & 100 \\
\hline $\begin{array}{l}\text { 20.Lack training courses to developed } \\
\text { competences }\end{array}$ & 86 & 14 & 14 & 1.86 & $93 * * *$ & 100 \\
\hline
\end{tabular}

Cut-off point $=1.5 *$ Low $=75, * *$ Moderate $=87.4, * * *$ High $=87.5-100$

Table (2): Distribution of Study Sample According to the Consequences of Workplace Violence Level

\begin{tabular}{|c|c|c|c|c|c|c|c|}
\hline \multirow{2}{*}{ A. On a personal level for Nurses } & \multicolumn{2}{|c|}{ Yes } & \multicolumn{2}{|c|}{ No } & \multirow{2}{*}{$\mathbf{R S}$} & \multirow{2}{*}{ MS } & \multirow{2}{*}{ Total } \\
\hline & No & $\%$ & No & $\%$ & & & \\
\hline 1.Resignation of someone from his/her job & 27 & 27 & 73 & 73 & 63.5 & 1.27 & 100 \\
\hline 2. Physical symptoms (injury, pain, crying, shouting) & 29 & 29 & 71 & 71 & 64.5 & 1.29 & 100 \\
\hline 3.Punishment including firing employees & 19 & 19 & 81 & 81 & 59.5 & 1.19 & 100 \\
\hline 4.Suicide (one participant one such case) & 7 & 7 & 93 & 93 & 53.5 & 1.07 & 100 \\
\hline 5.Isolation & 18 & 18 & 82 & 82 & 59 & 1.18 & 100 \\
\hline 6.Pity from friends at work & 26 & 26 & 74 & 74 & 63 & 1.26 & 100 \\
\hline 7.guilt feeling) & 39 & 39 & 61 & 61 & 69.5 & 1.39 & 100 \\
\hline 8. low self-respect & 43 & 43 & 57 & 57 & 71.5 & 1.43 & 100 \\
\hline 9.Feeling of being threatened & 47 & 47 & 53 & 53 & 73.5 & 1.47 & 100 \\
\hline 10. Less devotion and motivation to work & 46 & 46 & 54 & 54 & 73 & 1.46 & 100 \\
\hline 11.Negative effects on team work and interaction & 55 & 55 & 45 & 45 & 77.5 & 1.55 & 100 \\
\hline 12.Sleeping confusing & 66 & 66 & 34 & 34 & $* * 83$ & 1.66 & 100 \\
\hline 13.Anger & 73 & 73 & 27 & 27 & $* * 86.5$ & 1.73 & 100 \\
\hline 14.frustration & 54 & 54 & 46 & 46 & 77 & 1.54 & 100 \\
\hline 15.low productivity & 44 & 44 & 56 & 56 & 73 & 1.46 & 100 \\
\hline 16.absenteeism & 31 & 31 & 69 & 69 & 65.5 & 1.31 & 100 \\
\hline 17.Mental Fatigue & 67 & 67 & 33 & 33 & $* * 83.5$ & 1.67 & 100 \\
\hline 18.low morale & 67 & 67 & 33 & 33 & $* * 83.5$ & 1.67 & 100 \\
\hline 19.Work overloaded & 72 & 72 & 28 & 28 & $* * 86$ & 1.72 & 100 \\
\hline 20.Deterioration in quality of work as a result of fear & 45 & 45 & 55 & 55 & 72.5 & 1.45 & 100 \\
\hline \multicolumn{8}{|l|}{ B. On Work Level } \\
\hline 1Tension at work & 64 & 64 & 36 & 36 & 82 & 1.64 & 100 \\
\hline 2.Chaos at work & 60 & 60 & 40 & 40 & 80 & 1.60 & 100 \\
\hline $\begin{array}{l}\text { 3.Division of colleagues into two teams (one } \\
\text { supporting the aggressor and the other the victim }\end{array}$ & 53 & 53 & 47 & 47 & 76.5 & 1.53 & 100 \\
\hline $\begin{array}{l}\text { 4. Underestimation and disrespect of the profession of } \\
\text { nursing in the society }\end{array}$ & 74 & 74 & 26 & 26 & 87 & 1.74 & 100 \\
\hline 5.Absence of trust among colleagues & 51 & 51 & 49 & 49 & 75.5 & 1.51 & 100 \\
\hline \multicolumn{8}{|l|}{ C. On Health Care Setting } \\
\hline 1.Low quality of service & 70 & 70 & 30 & 30 & 85 & 1.70 & 100 \\
\hline 2.Reflection of a bad image of the healthcare setting & 78 & 78 & 22 & 22 & 89 & 1.78 & 100 \\
\hline 3.Physical damage of the healthcare setting & 68 & 68 & 32 & 32 & 84 & 1.68 & 100 \\
\hline $\begin{array}{l}\text { 4.More shortage of healthcare professionals (many } \\
\text { healthcare professionals shift to other fields }\end{array}$ & 80 & 80 & 20 & 20 & $90 * * *$ & 1.80 & 100 \\
\hline 5.feel relatedness to the organization and profession & 72 & 72 & 28 & 28 & 86 & 1.72 & 100 \\
\hline 6.Conflicts due to unclear job descriptions & 75 & 75 & 25 & 25 & 87.5 & 1.75 & 100 \\
\hline
\end{tabular}

Cut-off point $=1.5 *$ Low $=75, * *$ Moderate $=87.4, * * *$ High $=87.5-100$ 


\section{DISCUSSION}

Consequences of violence at work in the health sector have a significant impact on the effectiveness of health systems, especially in developing countries (ILO, 2002). The present study revealed that the highest percentage $(25 \%)$ of the study sample were at age group (40-44) years old, as shows in Figure (1). The mean age and SD of the study sample was $36.8 \pm 8.7$ years. However, more years of experience or higher educational qualification didn't appear to protect nurses. Senior nurse unit managers and clinical nurse specialists actually reported more physical assaults than less senior nurses. Age and gender didn't predict occurrence or type of incident either (Chapman et al, 2010). More than half (59\%) of the sample were male, this result disagree with ILO (2002), who reported that women are especially vulnerable. While ambulance staff is reported to be at greatest risk, nurses are three times more likely on average to experience violence in the workplace than other occupational groups. Since most health workers are women, the gender dimension of the problem is evident, Figure (2). Figure (3) shows that the highest percentage $(47 \%)$ of study sample were working in surgical ward. The initiative comes in the face of a mounting problem in hospitals and other health workplaces worldwide, both in developed and developing countries. Research shows that nearly 25 per cent of all violent incidents at work occur in the health sector and that more than 50 per cent of health care workers have experienced such incidents (ILO, 2002). Most (94\%) of study sample were living in Baghdad, as shown in Figure (4). Workplace violence affects all professional groups, genders and work settings in the health sector. The highest rates of offences, however, were reported by ambulance staff, nurses and doctors. Large hospitals in suburban are particularly at risk (ILO, 2002). The study revealed that the highest percentage (46\%) of study sample were at secondary school level, this result agree with study carried by Golubic et al, (2009) who find that nurses with secondary school qualifications perceived hazards at workplace and shift work as statistically significantly more stressful than nurses a with college degree as shown in Figure (5). (77\%) of study sample was married as shown in Figure (6). The findings indicated that the highest grade (92) at high level of RS of the work place sources regarding patient and his relative which refers to bad working conditions (excessive heat or cold, noise, bad furniture) as shows in table (1). Studies have shown that working conditions in healthcare environments place nurses and other healthcare personnel at greater risk of violence. Characteristics such as demanding workloads, inadequate staffing levels, interventions demanding close physical contact, emotionally charged environments, shift work, highly accessible worksites and poor security measures have been associated with increased incidents of violence (International Council of Nurses (ICN). 1999, Occupational Safety and Health Administration (OSHA), 2003). Also the results of the study shown the high RS mostly related to interfere with the nurse's work and treatment, Aggressive and impolite talk and Disturbing (verbal violence), this results agree with a study conducted by Chapman et al, (2010) who concluded that verbal abuse was almost universal, being reported by $92 \%$ of respondents. However, only half mentioned the incidents to senior staff or co-workers, and just $16 \%$ filed an official report. The reasons for not reporting are many and may include lack of time and management support and the belief that being attacked is 'just part of the job,"' as they wrote. Mitus (2011) considered that workplace violence ranges broadly, from offensive or threatening language to homicide. Healthcare patients are the source of more than half of nonfatal workplace assaults, with current and former co-workers accounting for 8\% (Wilburn, 2012). Mitus (2011) and Wilburn (2012) considered this type of violence may be constant or even routine. Forty-eight percent of nonfatal assaults in the workplace are committed by patients(National Institute for Occupational Safety and Health (NIOSH), 2002). Deeb (2003), concluded from study that all participants strongly agreed that nurses are the people who are most likely to be victimized in healthcare settings. Concerning colleagues or supervisors the highest grade (94.5) at high level of RS refers to absence of proper insurance, beside this result other results of the study shown the high RS mostly related to less motivation and reward to work, lack training courses to developed nurses' competences and lack of job security A study conducted by Golubic et al, (2009) identified six major groups of occupational stressors: 'Organization of work and financial issues', 'public criticism', 'hazards at workplace', 'interpersonal conflicts at workplace', 'shift work' and 'professional and intellectual demands'. Less motivation and reward to work. Washington State Nurses Association (WSNA), (2008) considered that the excessive workloads, unsafe working conditions, and inadequate support a form of violence and incompatible with good practice. According to table (2) which shows that the highest grade at moderate level of RS of the consequences on a personal level for nurses refers 
to anger, work overloaded, mental fatigue, low morale and sleeping confusing. Various literatures have noted that workplace violence has direct adverse impact on nurses' job performance which includes low productivity, absenteeism, low morale, turnover, demotivation, and anxiety. Hence, it is evident that violence at workplace adversely affects health care professional's personal and professional growth (Oxbridge Writers, 2011). Concerning consequences on work level the highest grade at moderate level of RS refers to underestimation and disrespect of the profession of nursing in the society, tension at work and chaos at work Excessive workloads, unsafe working conditions, and inadequate support can be considered forms of violence and incompatible with good practice (WSNA, 2008). Regarding consequences on health care setting as shown in table (2) the highest grade $(90,89,87.5)$ at high level of RS respectively refers to more shortage of healthcare professionals (many healthcare professionals shift to other fields, reflection of a bad image of the healthcare setting and conflicts due to unclear job descriptions, the impact of lateral violence and bullying in nursing were low staff morale, increased absenteeism, attrition of staff, nurses leaving the profession, and deterioration of the quality of patient care due to being distracted, unhappy, or intimidated (American Nursing Association, 2012). There were many reasons behind this problem through my observation during my professional experiences this may be due to weak position of women in the society, to limited knowledge and skills of nursing staff, to disrespect of nursing career, bad nursing image in Iraqi society and finally to lack of effective policy and procedures that can protected nurses in healthcare setting, this led many nurses to looking for other places either at same hospital or other places which be less contact with patients.

\section{CONCLUSIONS}

The study highlights the sources of workplace on nurses. All study samples had experienced workplace violence either from patient and his relatives or from colleagues or supervisors. Exposure to work place violence often has a great consequences regarding personal, working and health setting level on the satisfaction of nurses.

\section{RECOMMENDATION}

The present study recommends to create stable, safety, security and respectful workplace environment. In addition, it recommends raising the awareness among nursing staff by established violence prevention programs for all nursing employees to decreasing nurses' occupational violence and to maintaining their work ability. Finally, hospital managers should develop legislations to address and improve the quality of working conditions for nurses in hospitals.

\section{REFERENCES}

American Nursing Association. (2012). Workplace Violence.

Chapman, R. et al. (2010). Examining the characteristics of workplace violence in one non-tertiary hospital., J Clin Nurs. 19. P.p. 479-88.

Deeb, M. (2003). International Labour Office ILO International Council of Nurses ICN World Health Organisation WHO Public Services International PSI Joint Programme on Workplace Violence in the Health Sector LEBANON Country Case Study.

Guidelines for coping with violence in the workplace. (1999). International Council of Nurses (ICN). Geneva.

Golubic R., Milosevic M., Knezevic B., \& Mustajbegovic J. (2009). Work-related stress, education and work ability among hospital nurses, $J A d v$ Nurs. 65(10). P.p. 2056-66.

Henry, L. J., \& Ginn, G.O. (2004). Prevention of workplace violence. In D. L. Huber (Eds.), Leadership and nursing care management, Philadelphia: Saunders, (2006). P.p. 675692. Cited in Guidelines for Preventing Workplace Violence for Health Care \& Social Service Workers, U.S. Department of Labor Occupational Safety \&HealthAdministration (OSHA).www.OSH A.gov

Injuries and violence prevention in the framework of the ILO/ICN/ WHO/PSI Joint Programme on Workplace Violence in the Health Sector. (2000). Geneva. ector@ilo.org; International Council of Nurses. 3.

International Labour Organization (ILO, the World Health Organization (WHO), Public Services International (PSI) and the International Council of Nurses (ICN), (2002). "Framework guidelines for addressing workplace violence in the health sector" during a meeting at ILO headquarters in Geneva.

Jackson, D., Clare, J., \& Mannix, J., (2002). Who would want to be a nurse? Violence in the workplace-A factor in recruitment and retention, Journal of Nursing Management.10, 13-20. Cited in Guidelines for Preventing Workplace Violence for Health Care \& Social Service Workers, U.S. Department of Labor Occupational Safety \& 
Health Administration (OSHA). (2004). www.OSHA.gov

Mitus C M, (2011). Workplace Violence. Wild Iris Medical Education, Inc.

Occupational Safety \& Health Administration. (OSHA). (2003). (revised). Guidelines for preventing workplace violence for healthcare and social service workers. U.S. Department of Labor, Occupational Safety \& Health Administration. Washington, DC.

Oxbridge Writers. (2011). Problems encountered by nursing students - A study into violence, Oxbridge Writers: The UK's number one provider of custom essays from Oxford and Cambridge University qualified experts Oxbridge Essays Service.

Violence: Occupational hazards in hospitals, National Institute for Occupational Safety and Health (NIOSH). (2002). U.S. Department of Health and Human Services, Public Health Service, Centers for Disease Control and Prevention. Washington, DC.

Violence in the Workplace. (2008). Washington State Nurses Association WSNABoard of Directors, Position Paper, March 21.

Wilburn S, Workplace Violence. (2012). The Washington State Nurses Association Continuing Education Provider Program

Woelfle, C. Y., \& McCaffrey, R. Nurse on nurse, Nursing Forum. (2007). 42(3). P.p. 123-131. Cited in Guidelines for Preventing Workplace Violence for Health Care \& Social Service Workers, U.S. DepartmentofLabor Occupational Safety \& Health Administration (OSHA). www. OSHA.gov. 